\title{
Evidence of duration and type of illness in children found unexpectedly dead
}

\author{
C. SINCLAIR-SMITH, FAY DINSDALE, and JOHN EMERY \\ From the Department of Pathology, Children's Hospital, Sheffield
}

\begin{abstract}
Sinclair-Smith, C., Dinsdale, F., and Emery, J. (1976). Archives of Disease in Childhood, 51, 424. Evidence of duration and type of illness in children found unexpectedly dead. The thymus, rib, and liver from a series of 200 children found unexpectedly dead showed that in over $90 \%$ of these children the costochondral junction indicated that a retardation in growth velocity had preceded death. In a similar proportion of children the liver showed fatty change indicating a metabolic upset, which in $5 \%$ was of severe degree. Changes in the thymus compatible with a normal reaction to infection were observed in only a little over half of the child deaths. An absence of gross thymic reaction in some children in whom there was other evidence of infection suggests that in some an abnormal immunological reaction was taking place.

It is concluded that careful systematic clinical monitoring of growth in these children would have shown abnormality in nearly all.
\end{abstract}

More than half of the children dying between the ages of 2 weeks and 2 years die unexpectedly at home. They are frequently referred to as 'cot deaths' or 'crib deaths' and have been the subject of a large number of recent publications and of four recent symposia (Bergman, Beckwith, and Ray, 1970; Camps and Carpenter, 1972; Robinson, 1974; and Wedgewood and Benditt, 1965). As the majority of these deaths occur in overtly normal children they represent the greatest challenge in any scheme to reduce infant deaths.

For many years we have attempted an assessment of the nutritional and reactive state of children coming to necropsy. Thus we thought it useful to survey a sequential series of unexpected deaths of children to see what evidence we could obtain of a nonspecific nature on these children, to indicate whether or not a child had been healthy at the time of death, or for how long the child may have been ill before death (Emery, 1964). The three tissues used in the present study were the costochondral junction, the liver, and the thymus. The structure of the costochondral junction indicates derangement in the rate of growth, and whether the child has been suffering from a disease process such as subclinical rickets. It can also indicate the existence of previous phases of growth arrest.

Received 27 June 1975.
There are a considerable number of published reports about fatty change in the liver (Dible, 1951), and while it is arguable whether or not a completely normal liver contains free fat globules as seen on light microscopy, fatty change in the liver of any severity is usually accepted as an indication of a generalized metabolic upset of several days' duration.

The thymus usually reacts to the presence of infection by mobilizing lymphocytes from the cortex, and the degree and duration of an infective process can be reflected in the amount and type of cortical thymic discharge. The histological presence of active discharge of the thymic cortex and the evidence of active regeneration of cells within the thymus is an indication of the presence of what is usually an infective stress-producing situation (Metcalf, 1964).

Therefore, if a child is perfectly healthy the costochondral junction should be normal; there should be minimal or no free fat visible in the hepatocytes; and the thymus should not be showing a reactive change unless the child has recently had an infection.

\section{Materials and methods}

The materials comprised a sequential series of 200 children on whom necropsies were carried out by this department. All were referred through the coroner 
as being found either unexpectedly dead at home or dying within minutes of admission to hospital. The certified time of death has in recent years become a little unreliable as, if a child is found moribund, even clearly dead at home, unless it is cold it is immediately rushed to the Children's Hospital where active attempts at resuscitation are carried out, and death is frequently not certified until these resuscitation attempts have been abandoned.

The costochondral junctions were processed as described previously (Emery and Kalpaktsoglou, 1967) and the junctional area between the cartilage and marrow scrutinized for evidence of alteration in the cartilage columns and the presence of bridging, banding, and the occurrence of bizarre growth with varying degrees of osteoid formation.

Ribs. These ribs were divided into four categories (Fig.). (a) Normal; (b) evidence of recent arrest; diminished cartilage cell turn-over with the banking up of a layer of matrix between the end of the cartilage column and the growing bone, and bridging of the trabeculae across more than one column of cartilage cells; (c) prolonged arrest: considerable alteration in the

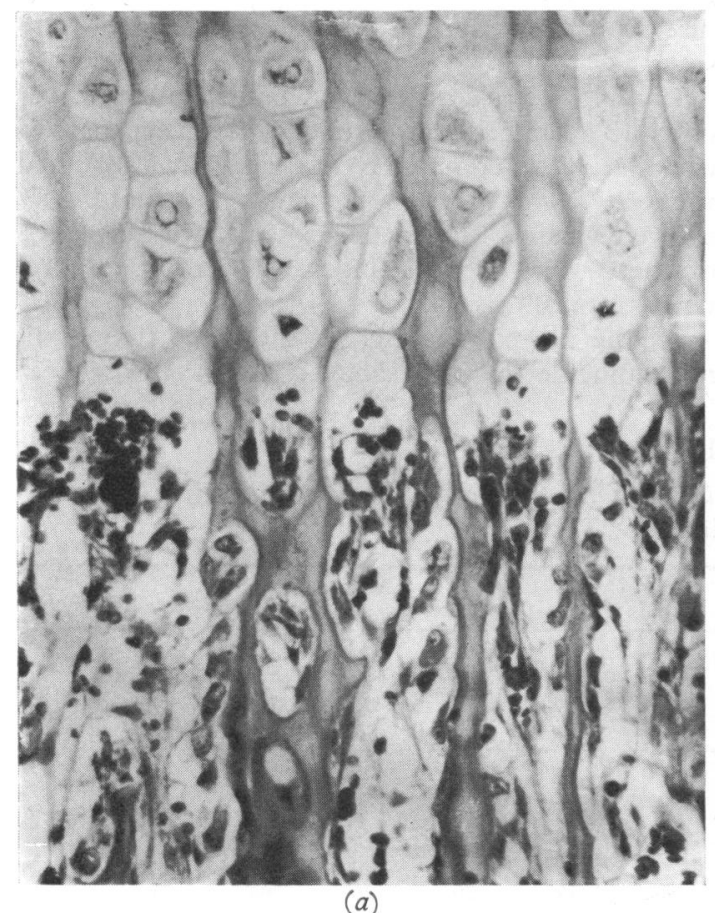

structure of the costochondral junction with wide pools of cartilaginous matrix and irregular bony trabeculae; (d) recurrent prolonged alteration: bands across the costochondral junction indicating phases of severe arrest in growth rate.

Thymus. The thymus was classified as (a) normal resting; (b) early starry sky: in which the cortical pockets show the presence of scattered large cells with pale cytoplasm containing phagocytosed lymphocytes; (c) full activity: in which phagocytosis is very marked and 'the stars in the sky' constitute a greater proportion of the sky than the densely packed nuclei of lymphocytes; (d) complete discharge of cortical pockets in many parts of the thymus with and without the presence of regenerated foci of thymocytes and together with the apparent reversed cellularity of the cortex and medulla, there being a greater concentration of thymic lymphocytes in the medulla than in the cortex; (e) involuted atrophic thymus: a small thymus with very prominent connective tissue, consolidation, and shrinking of the thymic lobes with prominence of cores.

The medullas of the thymuses were also surveyed and

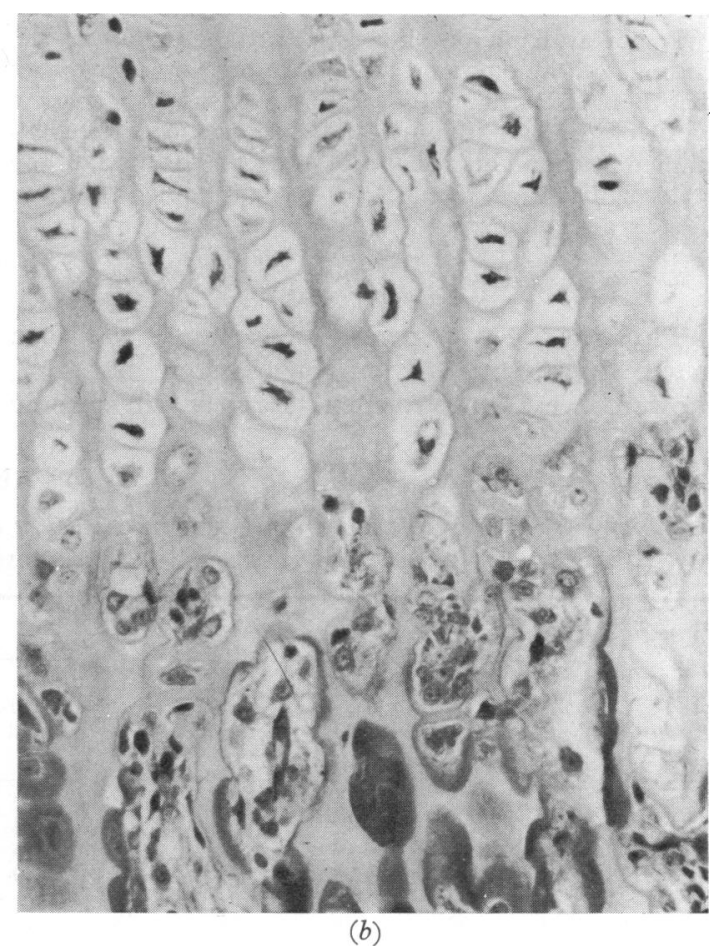
Fig.- - Showing the costochondral junction from 2 children both presenting as unexpected home deaths. (a) Shows a nearly
normal pattern with fairly regular columns of distended cartilage cells, some bursting into the marrow trabeculae to meet the oncoming blood vessels. (b) Shows a recent arrest of growth. The cartilage cells are compacted and there is a zone of matrix capping them. The invading marrow capillaries have penetrated right up to these indolent cells. Note also the irregularity and thickening of the osteoid-like tissue deeper in the rib. Such a rib indicates an arrest of growth probably lasting well over a week. $(\times 265$. 
the Hassall's bodies, but as no cases were found in which there was an absence of Hassall's bodies, these were not included in any classification.

Liver. Routine paraffin sections from both left and right livers were available in all cases, and fresh frozen sections of the fixed blocks of the liver were available from 59 cases. The liver sections were divided into 4 groups. (a) No fatty droplets visible, (b) a few fine droplets present in many cells, (c) coarse droplets present in all of the cells, (d) gross fatty change such as is frequently seen in children in the tropics undergoing severe malnutrition.

The left and right lobes were blocked separately and the lesion was recorded whether it occurred in either or both lobes. In no case was the difference between the two lobes sufficient to alter the category of the case. The frozen sections were assessed separately from the paraffin sections and the results later compared. The rating on frozen sections was consistently greater thau on paraffin sections and in many instances the frozen section showed the presence of fine fat vacuolation in liver cells not visible in paraffin sections. Fatty change was never reported on the paraffin sections when it was absent on the frozen sections. As the frozen sections were not available on all livers, only the results of the findings on the paraffin sections are presented, realizing that they represent an underestimate of the fatty change.

All of the rib, thymus, and liver sections were examined without knowledge of the case history of the child or diagnosis, the sections being obtained from the files by a technician.

\section{Results (Table I)}

Thymus. No evidence of discharge was seen in the thymus in $37 \%$ of the children, but $11 \%$ showed severe atrophy such as appears in chronic sepsis, and $8 \cdot 5 \%$ showed partial atrophy, indicating a very definite reaction. Thus $20 \%$ of children showed evidence of reaction such as occurs in prolonged bacterial infection. Of the thymuses showing early reaction, $30 \%$ showed what we term an early starry sky and $13 \%$ a definitely formed starry sky. Thus over $40 \%$ of children showed evidence of a response to what is probably an acute infection.

Rib. Only $5 \cdot 5 \%$ of ribs showed what we consider to be a normal costochondral junction. $49 \%$ showed evidence of prolonged arrest, and $14 \%$ of intermittent arrest. Since these changes are the least equivocal it appears that at least $60 \%$ of the infants showed evidence of retardation of growth as indicated by the rate of growth of the costochondral junction. Of the children showing a normal pattern of growth, none occurred in the A group, i.e. children with probable inevitable fatal disease, but it is of particular interest that only one normal rib was found in the 40 children in group D, i.e. the group which showed least evidence of overt disease at necropsy.

Liver. Regarding fatty change in the liver, only $13 \%$ of children showed a liver that we consider to be completely normal. In $52 \%$ small vacuoles were present in many cells, and 35\% showed what is essentially gross fatty change, $5 \%$ of these very gross changes as seen in children with tropical disease.

As the normal findings in the three tissues did not coincide in the same children the general

\section{TABLE I}

Summary of findings in thymus, rib, and liver in 200 children dying unexpectedly and divided into $5^{\star}$ types of necropsy findings

\begin{tabular}{|c|c|c|c|c|c|c|c|c|c|c|c|c|c|}
\hline \multirow[b]{2}{*}{ Group } & \multicolumn{5}{|c|}{ Thymus } & \multicolumn{4}{|c|}{ Rib } & \multicolumn{4}{|c|}{ Liver } \\
\hline & $\begin{array}{c}\text { Nor- } \\
\text { mal }\end{array}$ & $\begin{array}{c}\text { Early } \\
\text { Starry } \\
\text { sky }\end{array}$ & $\begin{array}{c}\text { Starry } \\
\text { sky }\end{array}$ & $\begin{array}{l}\text { Partial } \\
\text { atrophy }\end{array}$ & Atrophy & $\begin{array}{l}\text { Nor- } \\
\text { mal }\end{array}$ & $\begin{array}{c}\text { Recent } \\
\text { arrest }\end{array}$ & $\begin{array}{l}\text { Pro- } \\
\text { longed }\end{array}$ & $\begin{array}{l}\text { Inter- } \\
\text { mittent } \\
\text { arrest }\end{array}$ & $\begin{array}{c}\text { Nor- } \\
\text { mal }\end{array}$ & $\begin{array}{c}\text { Small } \\
\text { vacuoles } \\
\text { in many } \\
\text { cells }\end{array}$ & $\begin{array}{c}\text { Large } \\
\text { vacuoles } \\
\text { in many } \\
\text { cells }\end{array}$ & $\begin{array}{c}\text { Gross } \\
\text { fatty } \\
\text { change }\end{array}$ \\
\hline $\begin{array}{l}\text { A }(n=24) \\
\text { B }(n=55) \\
\text { C }(n=81) \\
\text { D1 }(n=38) \\
\text { D2 }(n=2) \\
\text { Total } 200\end{array}$ & $\begin{array}{r}7 \\
13 \\
33 \\
19 \\
2 \\
74\end{array}$ & $\begin{array}{r}7 \\
11 \\
27 \\
15 \\
0 \\
60\end{array}$ & $\begin{array}{r}2 \\
12 \\
10 \\
2 \\
0 \\
26\end{array}$ & $\begin{array}{l}6 \\
7 \\
3 \\
1 \\
0 \\
17\end{array}$ & $\begin{array}{r}2 \\
12 \\
8 \\
1 \\
0 \\
23\end{array}$ & $\begin{array}{r}0 \\
4 \\
6 \\
0 \\
1 \\
11\end{array}$ & $\begin{array}{r}7 \\
15 \\
23 \\
15 \\
1 \\
61\end{array}$ & $\begin{array}{r}12 \\
32 \\
38 \\
17 \\
0 \\
99\end{array}$ & $\begin{array}{r}5 \\
4 \\
14 \\
6 \\
0 \\
0 \\
29\end{array}$ & $\begin{array}{r}5 \\
8 \\
9 \\
4 \\
0 \\
26\end{array}$ & $\begin{array}{r}10 \\
28 \\
41 \\
24 \\
1 \\
104\end{array}$ & $\begin{array}{r}9 \\
15 \\
26 \\
9 \\
1 \\
60\end{array}$ & $\begin{array}{r}0 \\
4 \\
5 \\
1 \\
0 \\
10\end{array}$ \\
\hline
\end{tabular}

*A, children showing gross congenital deformities, inborn errors of metabolism, and degenerative conditions of the CNS from which death is probably inevitable.

B, children dying from recognized diseases such as pneumonia, meningitis, hypernatraemic uraemia, for which there is usually treatment. C, children in whom necropsy showed reaction to mild infection likely to cause symtoms but not necessarily death, such as tracheitis, mild gastroenteritis, otitis media.

D1, no definite diagnosable disease present but some evidence from examination of rib and liver of long-standing disease process.

$\mathrm{D} 2$, no lesion of any type found. 
TABLE II

Pattern of incidence of normal findings in 200 infants dying unexpectedly

\begin{tabular}{|c|c|c|c|c|c|}
\hline & Rib & Thymus & Liver & Number & Total \\
\hline $\begin{array}{l}\text { All normal } \\
\text { Normal in two } \\
\text { categories } \\
\text { Normal in one } \\
\text { category only } \\
\text { Abnormal in all categories }\end{array}$ & $\begin{array}{c}\mathbf{N} \\
\mathbf{N} \\
\text { Abnormal } \\
\mathbf{N} \\
\mathbf{N} \\
\text { Abnormal } \\
\text { Abnormal } \\
\text { Abnormal }\end{array}$ & $\begin{array}{c}\mathbf{N} \\
\mathbf{N} \\
\mathbf{N} \\
\text { Abnormal } \\
\text { Abnormal } \\
\text { Abnormal } \\
\mathbf{N} \\
\text { Abnormal }\end{array}$ & $\begin{array}{c}\mathrm{N} \\
\text { Abnormal } \\
\mathbf{N} \\
\mathrm{N} \\
\text { Abnormal } \\
\mathrm{N} \\
\text { Abnormal } \\
\text { Abnormal }\end{array}$ & $\begin{array}{r}2 \\
2 \\
8 \\
1 \\
6 \\
15 \\
61 \\
105\end{array}$ & $\begin{array}{r}2 \\
11 \\
82 \\
105\end{array}$ \\
\hline
\end{tabular}

pattern of findings of normality in related form is shown in Table II. Abnormality was seen in all three tissues in 105 children, 82 showed abnormality in two organs, of these, the largest group, were 61 children showing abnormal growth pattern indicated by the rib and fatty change in the liver, but with an apparently resting thymus. 11 cases showed abnormality in one organ. Only 2 children showed no reaction in the rib, thymus, or liver. Details of these 2 cases are as follows.

Case 1. A 3-month-old child who was apparently normal at birth. 2 days before death he was said to have a cold, was restless, and was wrapped in a blanket and laid on his right side in the evening at 6 p.m. When the mother went to give him his midnight feed he was found dead. The parents had never taken this child to the doctor and we have no records of the child ever having been taken to an Infant Welfare Clinic.

Necropsy showed no naked-eye abnormalities, but histology showed the presence of a diffuse infiltration of the epithelium of the trachea and bronchi with lymphocytes and a loss of ciliated epithelium. There was also some oedema of the lung, but no evidence of any recently inhaled material. The liver showed a moderate amount of hypoxic change only. No organisms were grown from the lower respiratory tract, but a moderate and pure growth of Streptococcus pneumoniae was grown from the middle ears. Thus the histological findings are those of a tracheobronchitis in a child with Strep. pneumoniae in the upper respiratory passages. From the appearance of the bronchioles in this child we would normally expect the child to have been reacting to a virus infection, but we do not know to what virus or how in this particular child this reaction resulted in death. We have, however, seen children admitted to hospital with severe respiratory symptoms dying with histological changes no greater than this, but such cases are extremely unusual. In our present classiffication this child is included under category $C$, in which evidence of disease is found (to which a name can be given) but the mechanism of death is not understood, and the lesion would not appear to be a common cause of death. He could well have died in a state such as has been postulated by Gardner (1968).
Case 2. A 4-month-old girl with a single older sib of 7 years. She weighed $2.7 \mathrm{~kg}$ at birth, was fed on Ostermilk, and was reported to have been gaining weight normally. The mother added milk of magnesia to the feeds for alleged difficulty in passing stools. The baby usually slept in the parents' bedroom and the father stated that on the day preceding death the child had been 'crying most of the day and night'. She was fed at 2 a.m. when she took only $90 \mathrm{ml}$ of milk and was found dead at 8.20 a.m. Necropsy showed bloodstained mucopus in the larynx, trachea, and bronchi, a congested lung with areas of what to the naked eye was thought to be early bronchopneumonia, and the intrathoracic thymus showed large numbers of petechiae. No evidence of bony or soft tissue damage was found in the child, and no other abnormalities were found. The histology did not confirm the naked eye impression of an acute pneumonia. The bronchi and trachea showed only an occasional mononuclear infiltrate. There were small groups of cells with an occasional hepatocellular degeneration in the liver but no other positive finding. The parents of this child did not accept our invitation to discuss the case with them.

Of the 11 children who were normal in two categories one was a child with hydrocephalus under treatment with a Holter valve who died unexpectedly, probably from some cerebral reflex abnormality, possibly of apnoeic unresponsiveness. (Wealthall, Whittaker and Greenwood, 1974). One child died with a Haemophilus influenzae tracheobronchitis, one with what was almost certainly severe hypernatraemic uraemia, and one died in the category which may be called 'gentle battering'. The remaining children showed histological evidence of a probable early virus infection of the respiratory tract.

\section{Discussion}

If our interpretation of the costochondral junction in children at necropsy is correct, we must accept that the vast majority of children found unexpectedly dead $(94 \%)$ were not growing normally at that time, and further that approximately $50 \%$ of children 
had been in a state of growth retardation for a considerable time. Apart from the small group (24 of the 200 cases studied) who were expected to be unwell - group $A$, those with clinically untreatable disease - the rest of the 200 children, i.e. 176, were not thought by the parents to be chronically ill. There is thus theoretically the probability that if the children had been regularly measured, an abnormality in growth velocity could have been picked up before their death.

Concerning the fatty change in the liver, the situation is slightly different. 10 of the children showed such a degree of fatty change that the definite possibility arises that these children were in some state of either poisoning or of an acute metabolic abnormality such as seen in Reye's syndrome. In none of these cases was such a diagnosis made, though in 6 of the 10 deaths no adequate cause of death was found. In only 26 of the children did the liver show no fatty change. The moderate degree of fatty change in the liver is probably not specific, but we have nearly always found it present in children showing any degree of hypernatraemia (Emery, Swift, and Worthy, 1974). The findings in the liver thus confirm the impression gained from the rib, that the majority of these children were unwell at the time that they died; there is a further suspicion that there may be some unrecognized disease process producing severe fatty change in the liver in a small group of these deaths.

The findings in the thymus differ in some degree from those in the rib and liver. There is a small group, approximately $20 \%$, in whom the thymus shows long-standing reactive changes and these cases were usually associated with children showing prolonged growth arrest in the rib. None of these cases had absent Hassall's bodies or, in that sense, any evidence of a chronic immunological deficiency state. $37 \%$ of the thymuses showed no apparent reactive state. This is extremely interesting in view of the findings of Huber and Baak in Holland (Baak, 1976) who did some quantitative histology on the thymus of a series of children found unexpectedly dead. They concluded that the characteristic feature in the thymuses is an increased thickness and cellularity of the thymic cortex, the very picture which we had used to indicate a resting thymus. This suggests that among these children found unexpectedly dead there are probably some reactions that we are not at the moment able to identify. Whether such reactions are those postulated by Gardner (1968) as being due to viruses, or by Coombs (1965) as a type of anaphylaxis certainly requires study.
In this study we have not attempted to identify the final pathways to death, nor have we, except perhaps very indirectly, investigated the role of hypoxia over a long-term period as proposed by Naeye (1973) but we have evidence through fatty change in the brain, that such a factor may be active in up to $50 \%$ of deaths (Gadsdon and Emery, 1976).

One thing seems certain, that we must not accept the popular concept that the majority of children found unexpectedly dead were previously healthy children. If these children had been very carefully monitored, and had growth velocity charts been available for them, in over $90 \%$ an alteration in growth rate would almost certainly have been identified before the children died. This does not of course mean that we know why they died.

This underlies our belief that the best way to prevent these children's deaths is to refine our means of identifying the children at risk and to submit these children to a much greater degree of care and attention than is now available.

\section{REFERENCES}

Baak, J. P. A. (1976). The thymus and sudden infant death syndrome. Histological Analysis.

Bergman, A. B., Beckwith, J. B., and Ray, C. A. (1970) (Editors). Sudden Infant Death Syndrome. Proceedings of the 2nd Intertional Conference on Causes of Sudden Infant Deaths. University of Washington Press, Seattle and London.

Camps, F. E., and Carpenter, R. G. (1972). (Editors). Sudden and Unexpected Deaths in Infancy (Cot Deaths). Report of the Proceedings of the Sir Samuel Bedson Symposium, Cambridge. Wright, Bristol.

Coombs, R. (1965). Sudden Death in Infants. Proceedings of the Conference on the Causes of Sudden Death in Infants, Seattle, Washington, p. 55. Ed. by R. J. Wedgewood and E. P. Benditt. Public Health Service Publication No. 1412, National Institute of Child Health and Human Development, Bethesda.

Dible, J. H. (1951). Degeneration, necrosis and fibrosis in the liver. British Medical fournal, 1, 833.

Emery, J. L. (1964). The assessment of the duration of illness in children unexpectedly dead. Medicine Science and the Law, 4, 39.

Emery, J. L., and Kalpaktsoglou, P. K. (1967). The costochondral junction during later stages of intra-uterine life, and abnormal growth patterns found in association with perinatal death. Archives of Disease in Childhood, 42, 1.

Emery, J. L., Swift, P. G. F., and Worthy, E. (1974). Hypernatraemia and uraemia in unexpected death in infancy. Archives of Disease in Childhood, 49, 686.

Gadsdon, D. R., and Emery, J. L. (1976). Fatty change in the brain in perinatal and unexpected death. Archives of Disease in Childhood, 51, 42.

Gardner, P. S. (1968). Virus infections and respiratory disease in childhood. Archives of Disease in Childhood, 43, 629.

Metcalf, D. (1964). The Thymus-its Role in Immune Responses. Springer, New York.

Naeye, R. L. (1973). Pulmonary arterial abnormalities in the sudden-infant-death syndrome. New England fournal of Medicine, 289, 1167.

Protestos, C. D., Carpenter, R. G., McWeeny, P., and Emery, J. L. (1973). Obstetric and perinatal histories of children who died unexpectedly (cot deaths). Archives of Disease in Childhood, 48,835 .

Robinson, R. R. (1974). (Editor). S.I.D.S. 1974. Proceedings of the Francis E. Camps International Symposium on Sudden and Unexpected Deaths in Infancy. Canadian Foundation for the Study of Infant Deaths, Toronto. 
Wealthall, S. R., Whittaker, G. E., and Greenwood, N. (1974). The relationship of apnoea and stridor in spina bifida to other unexplained infant deaths. Developmental Medicine and Child Neurology, 16, Suppl. 32, 107.

Wedgewood, R. J., and Benditt, E. P. (1965). (Editors). Sudden Death in Infants. Proceedings of the Conference on the Causes of Sudden Deaths in Infants, Seattle, Washington. Public
Health Serivce Publication No. 1412, National Institute of Child Health and Human Development, Bethesda.

Correspondence to Professor J. L. Emery, Department of Pathology, Children's Hospital, Thornbury, Fulwood Road, Sheffield S10 3BR. 